\title{
Comunicación

\section{Conflicto de leyes y censura en internet: el caso Yahoo!}

\author{
DAVID RAMÍREZ PLASCENCIA ${ }^{1}$
}

Este trabajo examina uno de los conflictos legales más importantes relacionados con la censura y la regulación de internet. Originado en el año 2000, el caso Yahoo! representa un hecho paradigmático no sólo por el problema normativo entre dos países, Estados Unidos y Francia, sino porque saca a debate los aspectos más problemáticos de la protección de la libre expresión en los medios de comunicación. Visto desde el aspecto legal, el caso Yahoo! nos alerta ante la posibilidad de la aparición de intromisiones judiciales extraterritoriales que, amparadas bajo el supuesto manto de la justicia, buscan imponer sus valores morales a los usuarios de internet.

PALABRAS CLAVE: internet, censura, concurrencia jurídica, extraterritorialidad.
This work examines one the most important legal conflicts related with censorship and Internet regulation. Originated in 2000, the Yahoo! Case represents a paradigmatic event, not only for the normative problem between two countries: United States and France, but it brings to debate the most problematic aspects of the protection of free expression in communication media. Viewing it from the legal aspect, The Yahoo! Case alerts about the possibility of extraterritorial judicial intromissions that sheltered under a doubtful justice, look to impose their moral values to the Internet users.

Keywords: internet, censorship, normative concurrence, extraterritoriality.

1 Sistema de Universidad Virtual, Universidad de Guadalajara.

Correo electrónico: davidrampla@yahoo.com.mx 


\section{INTRODUCCIÓN}

Hoy en día, la vida sin computadoras e internet, para millones de personas alrededor del mundo, sería impensable. Gran cantidad de empresas, universidades y dependencias gubernamentales se han apropiado de la red electrónica como herramienta fundamental para el desarrollo de sus operaciones cotidianas y sus proyectos institucionales. El número de seres humanos que hacen uso de este avance tecnológico suman ya más de 1,200 millones alrededor del mundo (e-consultancy: 2007); dicha cifra continúa en aumento, a pesar de contar con apenas 15 años de haber sido permitida su comercialización y generalizado su uso (Castells, 2001: 23).

Uno de los factores que ha propiciado la impresionante difusión de internet a escala mundial es, sin lugar a dudas, el haberse consolidado como uno de los medios de comunicación más baratos y eficientes que existen. La red se ha ido convirtiendo con el paso del tiempo en una fuente de información ilimitada y en un medio instantáneo para compartirla. Una nueva Biblioteca de Alejandría, donde el saber humano es almacenado en cantidades ilimitadas, pero también un poderoso sistema de comunicación que sostiene millones de interacciones entre personas prácticamente en tiempo real y con un costo casi nulo.

La red de redes también es un potencial símbolo de transparencia gubernamental. A través de ella se pueden crear portales virtuales que permiten a los ciudadanos tener acceso a información relacionada con la administración pública estatal: adquisiciones, enajenaciones, licitaciones y normativas. Internet es la globalización en su máxima expresión, y el ciberespacio el gran foro donde concurren personas de todo el mundo para conectarse entre sí con los más diversos fines.

Sin embargo, esos mismos beneficios que este adelanto tecnológico ha traído consigo también han sido causa de numerosos conflictos legales. En el plano nacional, los gobiernos han visto mermada su facultad para imponer leyes que controlen eficazmente la actividad de sus gobernados. Esta imposibilidad estatal parte, incluso, desde una cuestión básica que atañe a la identidad del usuario en línea. En la medida en que la red permite el anonimato, las posibilidades de que los usuarios hagan un uso impropio o ilegal se incrementan. De ahí que no hayan faltado 
opiniones de quienes consideren el combate al anonimato como una acción clave en los intentos de regular internet "

...a fin de poder exigir responsabilidades concretas y personales a quienes vulneran la libertad ajena en el abuso de la propia. (Cebrián, 2000: 145).

Ciertamente este asunto es importante para poder resolver el problema de la regulación de la red, pero lo cierto es que se necesita más que leyes estatales (Longworth, 2000: 11) para terminar este problema, teniendo en cuenta que ningún Estado u organismo internacional cuenta con el poder suficiente para hacer valer sus normas en todo el ciberespacio.

Y justamente esos problemas jurídicos de carácter internacional relacionados con internet comienzan a ser cada vez más comunes. Prácticamente desde los orígenes mismos de su comercialización, en la década de 1990, fue en aumento el número de actividades consideradas ilegales en uno o varios países. Desde la invasión de la privacidad de los usuarios que navegan en las infovías de la información por parte de empresas de marketing que recolectan datos de los cibernautas para establecer futuros clientes, hasta la violación de derechos de la propiedad intelectual y las actividades relacionadas con la pornografía infantil. Ya a mediados de los años 90 Wallace y Mangan (1997) habían identificado algunos de estos problemas legales: censura, protección de derechos de patente y privacidad, entre otros.

La carencia de fuerza coercitiva para hacer cumplir la ley que sufren los Estados-nación en el espacio virtual de la red, sumado a la falta de uniformidad en las disposiciones legales, son argumentos que quizá podrían orillarnos a pensar que el ciberespacio es un territorio virtual indómito y carente de regulación. Sin embargo, una de las principales premisas de este trabajo se asienta en el supuesto de que internet ya está regulada; de hecho ya había reglas en ella cuando fue creada, algunas de las cuales hacen alusión a su carácter flexible, descentralizado y tolerante. Dentro de las redes computacionales que la componen confluyen un conjunto de disposiciones legales, tanto estatales (gobiernos de países, organismos internacionales) como de índole privada (empresas, usuarios), que unidas dan forma a su cuerpo normativo, el cual no deja de ser en ocasiones contradictorio y conflictivo (Tantuico, 2001: 1; Car- 
bonier, 1982: 118). La problemática que gira en torno a la red de redes y su regulación se encuentra más íntimamente relacionada con la falta de coherencia entre las disposiciones legales que lo controlan, más que con la supuesta falta de regulación del mismo. Diferentes leyes tratan una misma conducta con base en criterios diferentes. Así, lo que para un Estado es ilegal, para otro está permitido.

Internet lejos de ser un espacio carente de regulación enfrenta la constante aparición de fenómenos de concurrencia normativa y conflicto de leyes, donde varios países e instituciones han regulado una misma conducta. Si bien este hecho, por sí mismo, no genera ninguna dificultad. El verdadero problema surge cuando hay dos regulaciones que concurren, pero que tratan esa conducta, en específico, de manera distinta. Esto provoca que conforme la red amplía sus horizontes alrededor del mundo, se vaya gestando, cada vez con más fuerza, un alto grado de incertidumbre legal, avivando el surgimiento de conflictos jurídicos a escala internacional, pues ya no es posible saber a ciencia cierta qué ley obedecer.

En este sentido, uno de los casos legales que más revuelo académico y judicial ha causado a nivel mundial, fue el suscitado entre la empresa estadounidense de servicios en línea Yahoo! y la asociación francesa Ligue contre le Racisme et l'Antisémitisme (LICRA). El análisis de dicho conflicto no sólo ha sido importante para la ampliar la comprensión sobre el fenómeno de la concurrencia de normas en internet, sino que también ha aportado referencias valiosas sobre el tema de la censura y los problemas éticos, legales y políticos que esta representa.

\section{YAHOO! VS LICRA}

La complejidad de regular la libertad de expresión, sin importar el país de que se trate, radica en que las normas que afectan tal actividad están basadas en juicios de valor, sean estos extensivos o no, al conjunto de la sociedad o propios de una elite burocrática. Normalmente, cuando las violaciones a convenciones morales se registran dentro de un país, tanto los presuntos infractores como sus jueces poseen un marco común de interpretación y acción. Sin embargo, esto adquiere una complejidad superior cuando ese marco no existe. Algunos actores podrían incluso no reconocer que se ha cometido una presunta violación. 
El caso Yahoo! vs LICRA ejemplificó esta clase de problemas. La venta de artículos nazis, objeto del conflicto entre ambas, es vista bajo dos lentes morales que difieren. Por un lado, en Estados Unidos la venta de tales artículos está permitida, dado que la primera enmienda constitucional avala el derecho de los ciudadanos a la libre expresión de las ideas, sin restricción alguna del gobierno. Así, la venta de cualquier mercancía no puede ser discriminada con base en criterios sobre la censura moral. Sin embargo, en Francia las cosas son diferentes: hay disposiciones legales impulsadas por los recuerdos de la ocupación de Alemania durante la Segunda Guerra Mundial y las reminiscencias del genocidio nazi presente en la memoria colectiva, por lo que está totalmente prohibido

usar o exhibir en publico una insignia o un emblema que evoque una asociación declarada como criminal, en este caso los artículos nazis (R-645-1 del código penal francés).

Este apartado pretende dar cuenta, de manera sucinta, pero completa, del proceso que tuvo como partícipes tanto a la empresa estadounidense de servicios en línea Yahoo!, como a la asociación francesa denominada LICRA, aunque, dicho sea de paso, esta última no estuvo sola, pues se le anexaron dos más: la UEJF (Union des Étudiants Juifs de France) y el MRAP (Mouvement contre le Racisme et pour l'Amitié des Peuples).

\section{Los actores...}

En 1995, David Filo y Jerry Yang fundaron una empresa que bautizaron con el nombre de Yahoo!. Su principal propósito era brindar al usuario de internet un catálogo de vínculos de sitios de interés general. Un mapa para guiar al cibernauta en su viaje virtual. En aquellos tiempos el ciberespacio apenas estaba, por así decirlo, en pañales, y los vínculos podían almacenarse sin problemas en los servidores de Filo y Yang. Sin embargo, la cantidad de sitios y de usuarios continuó en aumento, a tal grado que lo que empezó un buen día como un mero pasatiempo entre dos amigos, terminó por convertirse en una empresa multimillonaria que cuenta con importantes inversores como Sequoia Capital, Reuters Ltd. y Softbank, y que posee una plantilla de más de 9,800 trabajadores. 
Yahoo! cuenta no sólo con el ya mundialmente conocido servicio de búsqueda de sitios electrónicos, sino que también ofrece los servicios de correo electrónico, hospedaje de páginas web, mensajería instantánea, subastas en línea, a la par de otros servicios enfocados propiamente a las empresas: la publicidad y las asistencias de comunicación empresarial. Si bien Yahoo! obtiene ingresos por el hospedaje de almonedas virtuales, no puede ser considerada como la empresa líder en esta área. Ese lugar es ocupado por el gigante estadounidense "E-Bay" que cuenta con filiales quizá en todo el mundo. Comparada con esta última, Yahoo! es bastante modesta. Sin embargo, esta razón no fue suficiente para que no fuese el blanco de demandas en Francia por facilitar la oferta de artículos nazis, y hospedar grupos en línea donde se distribuían los textos antisemitas Mi lucha, de Adolfo Hitler, y Los protocolos de los sabios de Sión.

En Francia existen muchas organizaciones que luchan contra la discriminación antisemita. Probablemente su origen se remonte al siglo XIX, aunque su mayor auge se advierte durante la Segunda Guerra Mundial. Dichos movimientos no son aislados, sino que cuentan con una infraestructura bien establecida con miles de miembros. Muchos de sus integrantes se dedican a buscar de manera permanente sitios racistas, en especial contra judíos, y tratan de eliminarlos. No es de extrañar, entonces, que hayan reparado con cierta facilidad en los objetos nazistas mostrados en el portal de Yahoo!

De las organizaciones francesas que tomaron parte en este problema legal, la principal lleva por nombre la Liga Internacional contra el Racismo y el Antisemitismo (LICRA), que fue fundada en 1926 bajo el nombre de Liga Internacional contra el Antisemitismo (LICA), la palabra racismo sería agregada después, en 1979. Dicha organización se dedica, según se puede leer en su portal electrónico www.licra.org, a "defender la dignidad del hombre sin importar su raza, religión etc". Según se estipula en sus estatutos, no se necesitan requisitos especiales de ingreso ya que "cualquiera puede adherirse y militar dentro de esta asociación". Se menciona, de igual manera, que "no existe en su seno ninguna discriminación de carácter político y religioso, étnico y filosófico", salvo, claro, su actitud combativa frente la herencia nacionalsocialista alemana. En el apartado dedicado a la historia de la institución se hace énfasis 
especial en su participación en el caso Yahoo!, referido como un triunfo de la organización, pese a que, como se verá más delante, una corte en California exoneró a la empresa de servicios en línea.

Otra asociación francesa que se unió al litigio contra Yahoo! fue la denominada MRAP misma que surgió como un grupo de resistencia contra la ocupación alemana en Francia durante la Segunda Guerra Mundial, enfocándose a evitar la deportación de judíos a los campos de exterminio. A pesar de que los campos de concentración han terminado, al menos en la forma y sentido que le dieron los nazis (pues, desde luego, las cárceles estadounidenses en Guantánamo son una versión reciente de los mismos), esta agrupación ha seguido con la misión de salvaguardar los derechos de los judíos.

Una última agrupación que también estuvo involucrada en la demanda fue la UEJF, misma que desde sus orígenes, en 1944, se ha enfocado a ayudar y sostener a los jóvenes judíos de Francia. Hoy en día dicha organización cuenta con cerca de 15,000 miembros y posee una fuerte presencia en toda Francia.

Es posible apreciar cierta homogeneidad en cuanto a las agrupaciones francesas antes mencionadas. Pese a que se manifiesta en su nombre y estatutos que tienen alcances más amplios que los de ayudar y defender a los judíos, lo cierto es que en la práctica sólo se abocan a esta clase de objetivos. Con el arribo de internet, asociaciones de este tipo se han enfocado a la vigilancia de sitios de propaganda antisemita, aunque también, como en este caso, a vigilar la venta de insignias nazis en internet.

\section{La historia...}

En el año 2000 comenzaron a ser ofertados en subasta pública en el portal electrónico de la empresa estadounidense de servicios en línea Yahoo! (www.yahoo.com) una colección de objetos de la Segunda Guerra Mundial, en particular del III Reich. De igual forma, salió a la luz pública que en el servicio de hospedaje de sitios Web, denominado "Geocities", de la empresa antes mencionada, estaban a disposición de los usuarios de internet los textos antisemitas Mein Kampf de Adolf Hitler, y el texto Los protocolos de los sabios de Sión. Dado que esta empresa tiene como domicilio de operaciones California, y los servidores que soportaban tales operaciones se encontraban físicamente en 
Estados Unidos, tanto la subasta como la publicación de los textos antisemitas estaba autorizada y garantizada por la primera enmienda de la Constitución de los Estados Unidos de América.

Sin embargo, del otro lado del continente, en Francia, no tardó mucho en ser detectada la venta de estos objetos tan particulares por parte de las asociaciones judías antes mencionadas. De esta forma, en febrero del 2000 un activista dedicado a la búsqueda de sitios antisemitas en internet, el doctor en historia Marc Knobel, se da cuenta de esta subasta. Este descubrimiento sorprendió sobremanera a Knobel, pues para él, "Yahoo! era una comunidad de internautas, un mundo nuevo y mejor". En posteriores pesquisas el activista francés se enteró de que los objetos nazis ofertados sumaban alrededor de 800 , y que aunque la empresa no era la que los vendía, sino los usuarios del portal a través del servicio de subastas, la empresa obtenía regalías al proporcionar el servicio.

Entre finales de febrero y principios de abril, Knobel y su compañera Stéphane Lilti se dieron a la tarea de contactar a las asociaciones LICRA y UEJF para convencerlos de unirse contra estas subastas. Posteriormente, el activista contactó al periódico francés L'Express para realizar una entrevista. Durante la encuentro, Knobel sugirió al diario contactar a las empresas que se anunciaban en el sitio de Yahoo! en Norteamérica, www.yahoo.com, y preguntarles qué opinaban sobre el hecho de que el logo de sus respectivas empresas aparecía en el mismo sitio donde se subastaban los artículos nazis.

Al momento de ser cuestionados, tanto la compañía automotriz Ford como la de tarjetas de crédito Visa quedaron sorprendidos sobre el lugar que ocupaban sus banners en el portal de Yahoo!. Sin embargo, la compañía de automóviles solo se limitó a señalar que "no eran indiferentes ante tal situación, pero que las leyes que gobiernan la web son muy complejas". Por su parte, Visa señaló que pediría a Yahoo! que terminara el uso abusivo de sus anuncios. Poco después, el periódico L'Express contactó al vocero de Yahoo! sobre esta cuestión, el cual sólo se limitó a señalar que

prohibir los artículos Nazis sentaría un precedente peligroso en internet, pero que la empresa sí respetaba cierta moralidad, como por ejemplo, no se permiten la venta de animales vivos. 
La falta de interés de Yahoo! para suspender la oferta de tales objetos, obligaron a Knobel y Lilti a intentar una acción más agresiva, por lo cual decidieron contactar a LICRA para pedir su ayuda. Así, el 5 de abril, Yahoo! recibió una misiva de este organismo, previniéndolo de que si las subastas de artículos nazis continuaban en un plazo mayor a 8 días, los mismo se verían obligados a entablar una demanda judicial en una corte francesa. Sin embargo, antes de que el plazo hubiese expirado tanto Yahoo! como su filial Yahoo! Francia (www.yahoo.fr) fueron llevadas a juicio. A esta última se le reputaba el hecho de tener en su sitio electrónico un vínculo para acceder a su filial estadounidense; en otras palabras Yahoo! Francia sufrió la suerte de su filial en América, simplemente por tener una liga que conducía al portal de Estados Unidos. El temor de LICRA y el de las demás organizaciones que se anexaron a la demanda era que posiblemente algún ciudadano francés pudiera adquirir tales artículos en internet y que estos llegaran a Francia.

\section{El proceso contra Yahoo!}

Mucho antes de entablar una disputa legal, Yahoo! ya había sido condenado. En efecto, bajo un procedimiento legal francés denominado reféré, un juez en Francia puede establecer medidas precautorias antes de comenzar un juicio. De esta manera se ordenó suspender la subasta de artículos nazis, así como suprimir cualquier sitio en geocities.com, empresa perteneciente a Yahoo!, donde se almacenaba el texto de Mein Kampf, de Hitler y Los protocolos de los sabios de Sión.

Poco después de enterarse sobre la acción tomada por el juez francés, de apellido Gomez, Gleg Wrenn, consejero de asuntos extranjeros de la empresa estadounidense, se comunicó vía fax con el presidente de LICRA, Patrick Gaubert. En dicho documento se hacía patente el hecho de que Yahoo! era una institución que de ninguna manera aprueba las demostraciones de racismo, e hizo hincapié en los esfuerzos que esta empresa ha realizado mediante su filial Yahoo! Francia, en conjunción con la organización antisemita, para eliminar sitios nazis. Sin embargo, enfatizó que ellos no tenían ninguna facultad para actuar como censores. Ellos no proporcionaban el material, sólo hospedaban los contenidos. Se brinda un servicio en el cual no se tiene control sobre lo que los clientes publican. 
El 15 de mayo Yahoo! se presentó ante la corte francesa, lo cual pudo ser interpretado como la aceptación de la empresa estadounidense de su injerencia en este problema legal; sin embargo, como su consejero de asuntos extranjeros señaló en aquel momento:

la empresa sentía la imperante necesidad de explicarle a las autoridades francesas que los contenidos en disputa estaban almacenados en un servidor localizado en Estados Unidos. Los usuarios realizan un viaje virtual hacia el sitio en América de Yahoo!, por lo cual un juez francés no era competente para revisar el caso.

En efecto, uno de los primeros argumentos legales que tuvo que considerar el juez Jean-Jacques Gomez fue si era factible que una corte francesa tuviese facultad para dirimir este problema, o si, por el contrario, los abogados de la empresa tenían razón en sus alegatos sobre la falta de competencia. El juez llegó a la conclusión de que tenía la competencia para revisar esta controversia, puesto que se permitía la visualización en Francia de tales artículos, y la eventual participación de los franceses en las subastas. Yahoo!, desde esta perspectiva, había cometido una violación de la ley en Francia.

De esta manera, se asentó un precedente importante en el mundo sobre la actividad de los usuarios en internet. Así, bajo la mirada de la corte francesa, cualquier actividad que contravenga las leyes del país galo podría ser perseguida y castigada, sin importar el país en que se hubiese llevado a cabo y sin importar la intención del autor, o el conocimiento de la existencia de tal norma violentada.

El 22 de mayo la corte francesa dictaminó que Yahoo! incumplió la ya citada disposición R-645-2 del código penal francés, por lo cual se le condenaba a "tomar todas las medidas necesarias para evitar que los franceses pudieran entrar al sitio de yahoo.com." Igualmente, se le ordenó pagar los costos del procedimiento legal, los gastos de los demandantes, y una multa por concepto de daños para las organizaciones. Su filial en Francia fue obligada a implementar medidas tendentes a advertir a los usuarios sobre el riesgo de acceder a las subastas.

Yahoo!, no obstante, se negó a ejecutar sus disposiciones. Esta falta de diligencia por parte de la empresa obligó a las asociaciones francesas 
LICRA, UEJF y MRAP a pedir al juez Gomez que forzara el cumplimiento de la sentencia. Por otro lado, la empresa de servicios en línea siguió alegando la falta de competencia del juez para ver el caso. De cualquier forma, en una ordenanza con fecha del 11 de agosto, el juez francés volvió a negar los alegatos de Yahoo!, estableciendo, por el contrario, la designación de un colegio de tres expertos con la función de establecer a ciencia cierta si era factible o no el de evitar que los franceses ingresaran al sitio de las subastas.

El 6 de noviembre se instaló el colegio de expertos, compuesto por el francés François Wallon, el inglés Ben Laurie y el estadounidense Vinton Cerf, quienes rindieron un reporte especial en el que se indicaban dos métodos para evitar que los ciudadanos franceses ingresaran a las subastas nazis: el primero se refería a la utilización de un filtro de identificación basado en la IP (Internet Protocol, el lenguaje mediante el cual se comunican las máquinas entre sí dentro de la red): dado que todos los países manejan IP diferentes se podría establecer el lugar de donde se trataba de acceder al sitio. La otra opción se enfocaba a la utilización de un filtro que utiliza tanto una obligación de declaración de la procedencia geográfica del internauta, así como una vigilancia de las palabras claves utilizadas para ingresar. No obstante, los expertos llegaron a la conclusión de que ninguno de los dos métodos era totalmente seguro, sino que su alcance era cercano a 70\% de los usuarios, dado que alrededor de $20 \%$ de las personas utilizan una forma de acceso multinacional o, en su caso, una forma privada de comunicación. Dos semanas después de haber sido emitida esta declaratoria, el presidente del tribunal de primera instancia de París, el juez Gomez, emitió una tercera ordenanza en la que resaltaba lo siguiente:

En orden de satisfacer todos los requerimientos de la corte, Yahoo! tiene que conocer el origen geográfico y nacionalidad de los usuarios que pretendan entrar al sitio de subastas, así como prevenir a los usuarios radicados en Francia sobre los objetos en puja y prohibirles su entrada (County Court of Paris: 2000).

A Yahoo! France se le ordenó poner advertencias en el portal (www. yahoo.fr) sobre las subastas de artículos prohibidos llevadas a cabo en 
Estados Unidos, a través del portal yahoo.com. Finalmente, en la última parte de la ordenanza se cuantificaba la cantidad en francos franceses que la empresa estadounidense tendría que erogar por concepto de gastos del juicio, y las posibles sanciones en caso de incumplimiento:

1) En primer término se ordena a Yahoo! el cumplimiento de la ordenanza publicada el 22 de mayo del 2000 , dentro de los siguientes 3 meses seguidos a la publicación de esta ordenanza, bajo la pena de pagar una multa de 100, 000 francos por cada día de retraso.

2) El pago de 10,000 francos por el costo de las consultas realizadas, cifra que será depositada a un plazo de un mes.

3) Se tomó nota sobre la decisión de Yahoo! de terminar con el hospedaje del texto Los protocolos de los sabios de Sión.

4) Se obliga a Yahoo! a pagar a cada uno de los demandantes la cantidad de 10,000 francos.

A pesar de que Yahoo! tenía un plazo de dos semanas para hacer valer sus recursos de apelación, el 6 de diciembre del 2000 la empresa decidió pedir a un juez en California la revisión de la validez ejecutoria de la ordenanza de su contraparte parisiense. De esta forma el conflicto legal se trasladó a Estados Unidos.

\section{Del otro lado del Atlántico...}

California es uno de los estados más dinámicos de los Estados Unidos. Dentro de su actividad comercial destaca la industria cinematográfica, la agrícola, la vinícola en el Valle de Napa y, desde luego, el famoso Valle del Silicio (Sillicon Valley), ubicado en la zona sur del área de la Bahía de San Francisco, en el norte del estado. En esta área se ubican las oficinas centrales de las empresas más importantes de computación y alta tecnología como Apple Computers, Veritas y Adobe Systems. Es también la sede de las oficinas centrales de Yahoo!.

El 21 de diciembre del 2000 la empresa estadounidense inició un proceso legal ante la Corte del Distrito de California, radicada en San José, contra las organizaciones judías y los efectos de la ordenanza de la corte parisiense de mayo del 2000. Entre los principales argumentos legales se encontraban los siguientes:

a) Las leyes en Estados Unidos inmunizan a los proveedores de los servicios de internet ("ISP") de cualquier responsabilidad por el conteni- 
do publicado por terceras partes, como se puede apreciar en la sección 230 del Acto de Decencia de las Comunicaciones, 47 U.S.C Secc. 230.

b) La orden viola la política pública a favor de la libertad de expresión reconocida no sólo por los Estados Unidos como un derecho constitucional fundamental, sino también por tratados y leyes internacionales.

c) La orden ejerce una jurisdicción extraterritorial no-razonable sobre las operaciones y contenidos de los servicios web radicados en Estados Unidos, misma que pertenece a sus ciudadanos. La corte de París ha impuesto extraterritorialmente a una empresa estadounidense el remedio dramático de una futura restricción y penalidades que no son permisibles bajo la ley de Estados Unidos (Yahoo: 2000).

La carta principal de Yahoo!, para ganar el juicio, era tanto la excluyente de incompetencia del juez francés, así como la libertad de expresión. Si bien el argumento de la libertad de expresión requería un estudio más a detalle del caso, la otra objeción planteaba la misma pregunta que el juez Gomez se hizo en su momento ¿Se es o no competente para ver este caso? ¿Una corte en Francia puede obligar a un ciudadano en otro país a cumplir con una condena por un hecho cometido en su país de origen?

En enero del 2001 Yahoo! decidió eliminar de su servicio de subastas todo artículo controversial relacionado con la ideología nazi, aunque Yahoo! no censuró a ninguno de los grupos hospedados que tenían textos antisemitas, con lo cual solo cumplió parcialmente con las demandas francesas y el juicio legal siguió desarrollándose en las cortes estadounidenses.

Por aquel entonces hubo una gran movilización de asociaciones civiles a favor del respeto a la libre expresión, entre las que destacaban: "The Center for Democracy and Technology", "American Civil Liberties Union" y "Electronic Frontier Foundation". Fue por iniciativa de estas que el 6 de abril se optó por redactar un documento legal denominado "Amici Curiae"2, en el que hacían patente el peligro de

2 Escrito que puede tratarse de una opinión legal, un testimonio que no ha sido solicitado por las partes, o un tratado sobre el tema de la materia en 
que la censura legal de países extranjeros estableciera precedentes que estrecharían la libertad de expresión en Estados Unidos.

De igual forma, representantes de las organizaciones de lucha antisemita francesas redactaron un documento legal denominado "Moción para desechar", en el que argumentaban que legalmente no podían ser procesados en Estados Unidos porque, de la misma manera que Yahoo! alegó en Francia, la Corte de San José no tenía jurisdicción sobre ellos, por lo cual solicitaban al juez californiano que desechara la demanda de Yahoo! contra ellos.

Sin embargo, el 7 de junio del 2001, el juez Jeremy Fogel denegó los alegatos de los franceses, redactando una orden judicial mediante la cual se negaba la solicitud de desechar la demanda de Yahoo!, aseverando lo siguiente:

Si bien los demandados no tienen un contacto continuo con California, y que esta corte carece de jurisdicción general sobre los mismos, este tribunal busca, sin embargo, resolver la cuestión de si tiene una jurisdicción específica sobre los demandados, en este caso legal en particular (District Court for the Northern District of California: 2001a).

Para encontrar esta jurisdicción especial, el juez Fogel hizo uso de un test para decidir si las asociaciones francesas habían realizado acciones tendentes a crear dicha jurisdicción en Estados Unidos. Entre las pruebas con más peso que fueron tomadas en cuenta para dirimir este asunto, se encontraban:

a) La carta que envió LICRA a Yahoo!, que buscaba que esta se desistiera y cesara de subastar los artículos nazis, tenía como destino las oficinas centrales de la empresa en Santa Clara, California.

b) Los demandados solicitaron a la corte francesa que Yahoo! realizara ciertas acciones con sus servidores en Estados Unidos.

c) Los demandantes solicitaron la ayuda de los US Marshalls para la ejecución de la sentencia en California (idem).

disputa y que puede ser tomado o no en consideración por el juez al dictar su sentencia. Tech Law (http://www.techlawjournal.com/glossary/legal/ amicus.htm 
Después de valorar las pruebas, el juez aceptó que tenía jurisdicción especial sobre los demandados y rechazó su recurso, instando a los mismos a contestar la demanda en un plazo no mayor de 20 días a partir del día en que la orden fue redactada (junio 7).

En noviembre del 2001 salió a la luz pública la decisión judicial del juez de San José sobre la materia principal del conflicto entre Yahoo! y LICRA. Lejos de ser una sorpresa, el documento de 24 páginas sólo reafirmaba lo que se estuvo manejando en los círculos legales estadounidenses, dado que dejó sin efectos las disposiciones de la corte francesa con relación a las subastas de artículos nazis.

Sin embargo, la corte californiana no trató de entrar en controversia con su similar en París, por lo que dejó muy en claro que sólo se pronunciaría con relación al asunto de las subastas. Como se puede apreciar de forma clara en el texto judicial, no se trataba de ninguna manera acerca de "la aceptabilidad de promover símbolos o propaganda del nazismo. La mayoría concordaría que tales actos son profundamente ofensivos". Así, la corte de San José no cuestiona las motivaciones que tuvieron las autoridades francesas sobre las políticas de censura sobre tales objetos. Tampoco es cuestión a resolver en este juicio, continúa más adelante el juzgador, "cuestionar el derecho de Francia o alguna otra nación de determinar su propio ley y políticas sociales. Una función básica de un Estado soberano es determinar por la ley cuáles formas de expresión y conducta con aceptables dentro de sus fronteras". Lo que es el asunto a tratar por esta corte, continúa el documento es:

si es consistente con la Constitución y las leyes de los Estados Unidos que otra nación regule la expresión de los residentes estadounidenses dentro de los Estados Unidos, en el supuesto de que tal expresión pueda ser accesada por los usuarios de internet de esa nación (District Court for the Northern District of California : 2001b).

La corte, por último, dejó en claro que el cumplimiento de la orden francesa en territorio estadounidense no era compatible con la protección a la libre expresión consagrada en la primera enmienda de la Constitución. De tal forma, la misma quedaba sin efectos legales y la empresa de servicios en línea no tendría que cumplir sus lineamientos, 
sin importar si ella contaba con la posibilidad de hacerlo. A las asociaciones francesas sólo les quedó utilizar el recurso de apelación, mismo que tardaría más de dos años en ser dirimido y cuya resolución final sostuvo en el 2004 la sentencia del juez de California. De entre los puntos rescatables de la resolución de la corte de apelaciones resalta lo siguiente:

A pesar de algunos factores de peso a favor de los apelantes, estos han fallado en presentar un caso concluyente para demostrar que el juez de distrito en California ejerció una jurisdicción no-razonable sobre los mismos

Con esto se declaraba que la sentencia legal no estuvo viciada por falta de competencia. Después, se dio el veredicto donde se sostenía el fallo legal que se había emitido en el 2001. Con ello terminaban, aparentemente, las aspiraciones de las asociaciones francesas por hacer cumplir la sentencia de la corte parisiense.

Sin embargo, en enero del 2006, otra corte de apelaciones, en esta ocasión, la del circuito noveno de Estados Unidos (US 9th District Court Decision, 2006) se negó a pronunciarse en favor de Yahoo!. En una decisión cerrada, la corte declaró

que dado que la empresa estadounidense había accedido a seguir algunas de las disposiciones de la corte francesa, el caso en disputa se había vuelto incierto... [asimismo se aseveró que] las cortes estadounidenses no tiene ninguna jurisdicción sobre leyes francesas que prohíban la subasta de artículos nazis.

De esta manera, si bien Yahoo! no tendría que ser castigado en Estados Unidos como consecuencia de la sentencia en Francia, también quedaba claro que ninguna corte estadounidense puede hacer nada en contra de las sentencias francesas emitidas en su ámbito soberano.

\section{ANÁLISIS Y CONCLUSIONES}

La jurisdicción sobre los hechos en disputa en el caso Yahoo! nunca fue del todo clara. No fue posible establecer a ciencia cierta si se trataba de 
un asunto francés o, por el contrario, la venta de artículos nazis debería de ser juzgada bajo el punto de vista estadounidense. Esta clase de problemas no son de ninguna forma fáciles de resolver, porque atañen a distintas formas de ver los hechos y confluyen aspiraciones encontradas. Sin embargo ha habido esfuerzos importantes para poder dilucidar tales problemas. Así, para poder establecer los límites jurisdiccionales en el caso legal de Yahoo! es posible acudir a tres supuestos importantes, de acuerdo a Barbry (2002).

El primero hace énfasis en que la jurisdicción debe ser determinada en función del origen de los contenidos publicados en internet. En este sentido, el estado que tiene derecho a dirimir la controversia es aquel donde se llevó a cabo la acción. Así con relación al conflicto entre Yahoo! y LICRA, el país que tiene el derecho de juicio es Estados Unidos. Sin embargo, al tratarse de un asunto sobre los límites de la libertad de expresión, el mismo nunca se hubiera realizado, dado que la Primera Enmienda de la Constitución estadounidense protege los contenidos que Yahoo! publica en su sitio.

Para muchos críticos, el problema de aplicar este criterio sería la posible creación de paraísos ilegales donde los delincuentes cometerían ilícitos como piratería, pornografía infantil, terrorismo. Estos contenidos podrán ser almacenados y publicados en países donde no son considerados ilegales, o donde las autoridades carecen de medios para detenerlos, o simplemente sean fácilmente sobornadas. Esta preocupación, sin embargo, no justifica de ningún modo la intervención extranjera en un país. Hay muchas cuestiones en internet que no son uniformes; por ejemplo, lo que en un país representa la violación de un derecho de copyright, en otros lugares no lo es de ningún modo. Entonces, bajo el pretexto de acabar con estos "paraísos" se fundamenta una intervención que no muchos países estarían dispuestos a tolerar.

Otro criterio jurisdiccional, contrario al anterior, se centra en la idea de que el derecho de dirimir tales controversias debe descansar en la autoridad del país que es afectado por el acto. Esta fue la base en la cual el juez Gomez se apoyó para establecer su competencia sobre la empresa estadounidense Yahoo! y dictar su sentencia. Bajo esta postura, no habría ningún contenido en internet que de ser considerado ilegal por un país en particular, no pudiera ser condenado por infringir una ley extranjera, sin 
importar si se tenía conocimiento de la misma o cual fuera la nacionalidad del infractor. Los creadores de sitios electrónicos en internet tendrían que prever que sus contenidos sean acordes no sólo con la legislación de su país, sino con las normas de todos los países del mundo.

Lejos de plantear las muchas deficiencias sobre justicia que lleva aparejadas la aplicación de este criterio jurisdiccional, lo cierto es que representa, por sí mismo, un grave problema de aplicabilidad. Si bien un país puede en cualquier momento legislar todo lo que pasa en internet y elaborar grandes volúmenes de códigos legales, eso no implica que tenga el poder coercitivo para lograr que tales normas sean cumplidas. Hace falta la cooperación del país de origen para cumplir tal disposición, pero no es fácil lograr que un país determinado permita el cumplimiento de una sentencia de una corte extranjera en su propio territorio.

Un último principio jurisdiccional plantea que el derecho de juzgar un acto ilegal pertenece al país a cuyos ciudadanos va dirigida tal comunicación. A grandes rasgos, lo que sugiere este criterio es que la competencia de un sitio en internet puede ser determinada con base en las personas a las que va dirigido. Esto puede ser determinado según el idioma en que está redactado, el origen de las personas que lo hicieron y el tipo servicios que ofrece. Si bien con esta teoría se podría establecer fácilmente la jurisdicción en algunos sitios, en otros no sería tan simple. Muchos de ellos utilizan el idioma inglés por razones de difusión, aunque no sea su lengua nativa, y el alcance de los contenidos es de carácter general, lo cual nos dejaría sólo el criterio del origen de los contenidos. El sitio de subastas de Yahoo! está dirigido principalmente a los consumidores de Estados Unidos, y no es prioridad buscar clientes en Francia o en otro país. Para eso existen sitios propios de Yahoo! que manejan el idioma y los contenidos de esos países.

Muy a pesar de lo difícil que es determinar la jurisdicción en internet, algunos autores se han abocado a fundamentar el derecho de la corte francesa para haber llevado a juicio a Yahoo!. Así, se ha manifestado que el juez en Francia no trató de ningún modo de juzgar a la empresa estadounidense por los actos que esta realizó en Estados Unidos, pero sí que tenía derecho a juzgarla por las repercusiones que dichos actos tuvieron en Francia (Penfold, 2001:13). 
Uno se preguntaría si este argumento pudiera ser valido, sin considerar primero las intenciones o el conocimiento del infractor. Hay muchos casos similares que pueden ser citados, en los que se llega a violar leyes de ciertos países por acciones consideradas legales en otro. Un caso representativo fue la controversia entre algunos organismos estadounidenses y el gobierno mexicano sobre unas estampillas de correo dedicadas a un personaje de historietas mexicano llamado "Memín Pinguín". Este personaje de raza negra, muy popular en México, no tiene una connotación racista explícita $\mathrm{o}$, al menos, es controvertible que lo tenga. Pero en Estados Unidos algunos grupos pro derechos de los afroamericanos se declararon en contra de la estampilla, considerándola racista. En el hipotético caso de que la corte estadounidense se hubiese pronunciado en contra de las estampillas, se podría argüir erróneamente que el Poder Judicial se manifiesta en contra, no del acto de vender estampillas de este personaje en México, sino de las repercusiones de tales ventas en la población de Estados Unidos. Esta clase de argumentos lo único que provocan son intervenciones internacionales disfrazadas, donde se trata de imponer principios morales ajenos a tal país.

Siguiendo esta línea de razonamientos, se suele declarar que los conflictos como el de Yahoo! tienden a parecerse mucho a los problemas ambientales globales, donde la emisión de gases invernadero afecta no sólo al país de origen, sino que el mismo influye en el calentamiento global de la Tierra. Sin embargo, tal comparación tiene algunos inconvenientes. Uno de ellos se relaciona con el hecho de que los efectos de estos gases no pueden evitarse, es decir, afectan el clima en otros países de modo inexorable. En internet, en cambio, se necesita que el usuario acceda a esta clase de sitios. Es decir, la información está potencialmente ahí, pero es el cibernauta el que debe navegar hasta ella. Los artículos nazis estaban ofertados en Yahoo!, pero para conseguirlos hay que entrar al sitio. Muchos países tienden a considerar posible el derecho de censurar los contenidos virtuales que no desean que sus ciudadanos vean, pero se trata de una medida cuya compatibilidad con el respeto de las libertades civiles es dudosa. Cada usuario es responsable de los sitios que visita y la información que maneja.

Para algunos autores, no quedaba lugar a dudas que bajo los ordenamientos legales franceses el juez Gomez revestía la suficiente autoridad 
para citar a Yahoo!. Este derecho está sustentado en decisiones judiciales en las que se instituyó el principio legal que "extiende al orden internacional las reglas internas de competencia". Así también, bajo el artículo 14 del código civil francés, es posible que un extranjero que no reside en Francia pueda ser citado ante los tribunales franceses (Kosma, 2001). Pero lo cierto es que, incluso en Francia, esta jurisprudencia sobre la cual se basó el juez para traer a Yahoo! delante de la justicia, no ha estado exenta de críticas. Pues el hecho de que exista un sustento legal clásico, no significa que el mismo no deba, de ningún modo, evolucionar, o que incluso su aplicación sea siempre pertinente (Sédallian, 2000: 3).

Autores como Michael Geist (2001:1), por el contrario, creen que casos como el de Yahoo! demuestran que los gobiernos de los estados han comenzado a querer extender su poder de normar internet. Habría que plantearse entonces la objeción de que normar no es lo mismo que controlar. Hace falta más que un texto escrito para controlar los fenómenos en la red: ¿de qué sirve instituir normas que regulen las acciones de los actores en el ciberespacio, si no se tiene el poder para hacerlas valer, si no se cuenta con la infraestructura suficiente para vigilar, supervisar, juzgar y castigar todos los contenidos almacenados en los servidores en el mundo? Una cosa es querer juzgar a una empresa como Yahoo! con una alta presencia en internet, y otra es constreñir el accionar de 1,200 millones de usuarios. Eso es querer matar moscas a cañonazos.

Algunos escritores elevaron por mucho sus expectativas sobre el presente caso, augurando importantes beneficios para la "democracia". Reidenberg (2001:2) interpretó el veredicto de la corte francesa como un "triunfo que promoverá los valores democráticos en internet y su respeto". Barbry (2002:3) afirma que el juez Gomez no trató de ninguna forma de imponer la ley francesa sobre Yahoo!, pues de haberla impuesto se habría ordenado el cierre total del sitio. El sentido de su resolución se concretó a pedir a la empresa californiana que no permitiera a los franceses que entraran a su sitio de subastas. Lo anterior no es de ninguna forma acertado. En primer lugar, el juez parisiense se basó en que el sitio web de la empresa estadounidense podría ser visitado por ciudadanos franceses, tanto a través del portal de Yahoo! Francia (www.yahoo.fr), como directamente en internet en la dirección www. 
yahoo.com. Es decir, aplicó el criterio jurisdiccional sobre la afectación del sitio porque se le acusó de haber banalizado el nazismo, y lo condenó a evitar que los ciudadanos franceses no entrarán al sitio de subastas, bajo pena de una multa.

En esta parte es menester analizar la otra cara de la moneda, es decir, las críticas en contra de la sentencia de la corte parisiense. Estos argumentos no son de ningún modo parciales, o sea que pertenecen tanto a tratadistas franceses como a estadounidenses y a otros países. Los mismos tienden a ser muy específicos en cuanto a sus críticas, siendo la naturaleza de los objetos en disputa uno de los puntos más atacados, así como los alcances globales del sitio Yahoo! y la influencia de sus contenidos en Francia.

Para Etienne Wery (2000) un aspecto muy importante para tomar en cuenta sobre el alcance global de las subastas es analizar las características particulares del sitio en donde fueron ofertadas. En el caso de Yahoo!, su naturaleza local era evidente: es un sitio redactado en inglés, el precio era en dólares y tanto el modo de venta y los objetos requerían una dirección física. Estas características hacían que el criterio francés de competencia fuera muy débil para atraer a Yahoo!.

En términos generales, las pruebas que otorgan a las leyes francesas una aplicación extraterritorial no son de ninguna manera razonables. Para Sédillan (2000:3) los mismos deberán acoplarse a la naturaleza particular de internet, porque de lo contrario cualquier sitio virtual, sin importar el lugar donde se haya erigido, puede ser juzgado bajo la justicia francesa. Otro punto a tomar en cuenta es si la venta de artículos representa por sí mismo un intento de banalización del nazismo. El asunto, como se puede suponer, es tremendamente difícil de zanjar. Ya en 1997 una corte de apelaciones, en París, había denegado una demanda para prohibir una venta de artículos nazis por catálogo. La decisión se basó en el argumento de que ningún texto legal prohibía la venta de tales objetos; asimismo, se asentó que una cosa no es necesariamente portadora de una mensaje antisemita por sí misma, sino que hacía falta que al mismo estuviera adherido un mensaje que manifestara una acción de discriminación. En esta dirección, una decisión de la corte de casación, que data del 18 de marzo del 2000, señalaba que la venta de un artículo nazi no representaba por sí misma una acción de banalizar el nazismo o el antisemitismo. 
Incluso los criterios de la corte parisiense no han sido de ningún modo uniformes. Por ejemplo, en 1996, ante una demanda interpuesta por la UEJF para que se ordenara a algunas empresas francesas de acceso a internet que imposibilitaran a sus clientes el acceder a mensajes de corte antisemita, el mismo tribunal que condenó a Yahoo! (aunque no el mismo magistrado) denegó a esta asociación francesa sus peticiones, esgrimiendo, entre otras aspectos, el importante principio de libertad de expresión del cual el Poder Judicial era guardián, y que no conocía límites más que los establecidos de manera estricta. Paradójicamente, estos mismos argumentos serían usados después por la corte de Estados Unidos para liberar a Yahoo! de la sentencia francesa (ibidem: 6).

Un punto interesante con relación a los objetos en disputa es el hecho de que no todos representaban expresamente alguna connotación nazi o antisemita. De hecho, entre los artículos que estaban siendo subastados se podrían encontrar timbre postales (uno de ellos, por cierto, en contra de Hitler), monedas, modelos de avión de la Luftwaffe, entre otros.

Más allá de la fuerza de los argumentos en contra de imponer criterios como los usados en el caso Yahoo!, no hay duda de que los sitios web no pueden considerarse a salvo de ser perseguidos por violar leyes de países diferentes a donde son emitidos. Esto indica que los jueces han encontrado un vínculo jurisdiccional para juzgar el contenido de portales situados fuera del país, aunque el cumplimiento de esta clase de sentencias judiciales dependerá de las diferencias sobre libertad de expresión en los países (Kohen, 2003:17). Lejos de ser esta una predicción apocalíptica, los hechos han comenzado a respaldarla. Por las mismas fechas del caso Yahoo! se sucedieron en Europa una serie de conflictos legales donde el Poder Judicial se pronunció a favor de castigar a infractores que colocaran contenido nazi en internet, sin importar la nacionalidad u ubicación del trasgresor con tal de que dichos contenidos estuviesen disponibles en Alemania a través de internet. La Suprema Corte alemana señaló que las normas germanas sobre los escritos de odio racial, mismas que prohíben la propaganda nazi, son aplicables en internet a toda persona sin importar su nacionalidad. Este caso se aplicó a los escritos distribuidos por el australiano, alemán de nacimiento, Frederick Toeben. En este mismo sentido una sentencia de la corte italiana 
aceptó una demanda interpuesta por un israelí residente en Italia, que había sido sujeto de difamaciones difundidas en un sitio en internet fuera de este país (Fagin, 2003: 431).

Es importante considerar, sin embargo, que a pesar de estas claras muestras de capacidad y disposición de los estados para encontrar una jurisdicción y aplicar leyes específicas en internet (ibidem: 421), una cosa es normar un fenómeno y juzgar a las personas o empresas que violan la ley, pero otra es hacer cumplir dicha sentencia. De cualquier forma todo indica que conforme la red se expanda en todo el mundo, será cada vez más común encontrar casos como el de Yahoo!. Hacia dónde se incline la balanza dependerá, entre otras cosas, de la voluntad de los actores que conviven en la red y del entramado de intereses que entren en juego.

\section{Bibliografía}

AMERICAN CIVIL ASOCIATIONS (2001) Brief Amici Curiae in Support of Yahoo! Inc.'s Motion for Summary Judgment, USA.

AMERICAN Commerce Asociations (2001) Brief Amici Curiae, USA

BARBRY, Eric (2002) "Loi aplicable et juridictions competentes pour les sites internet" France: Le Journal du Net, en http://www.journaldunet.com/

CARBONIER, Jean (1982) Sociología jurídica, Madrid: Tecnos.

CASTELlS, Manuel (2001) The Internet Galaxy, New York: Oxford University Press.

CEBRIÁn, José Luis (2000) La Red, España: Punto de Lectura.

COUNTY Court of Paris (2000) "Interim Court Order No. RG. 00/5308", France (english version).

DISTRICT Court for the Northern District of California (2001a) “Order denying motion to dismiss", USA.

- (2001b) "Order Granding motion for summary judgment”, USA

E-CONSULTANCY (2007) consultar en www.e-consultancy.com

FAGIN, Matthew (2003) "Regulating Speech across borders: technology vs values", 9 Mich. Telecomm. Tech. L. Rev.

GEIST, Michael (2001) "The legal implications of the Yahoo! Inc. nazi memorabilia dispute: an interview with professor Michael Geist" Juriscom.net, en http://www.juriscom.net 
INSEAD (2001) Business e-Ethics: Yahoo! on trial. Francia: The european case clearing house, en www.ecch.cranfiel.ac.uk

KOHEN, Marcelo (2003) "Europe and the standardization of the law: past and present", Graduate Institute of International Studies, Geneva, en http://hei.unige.ch/sections/dr

KosmA, Catherine (2001) Affaire Yahoo! "Implications juridiques et économiques", Francia: Net Iris, en http://www.net-iris.fr

LONGWORTH, Elizabeth (2000) "The possibilities for a legal framework for cyberspace including a New Zealand perspective", in UNESCO (2000).

PENFOLD, Carolyn (2001) "Nazis, porn and politics: asserting control over internet content". United Kingdom: The Journal of Information, Law and Technology, en http:// elj.warwick.ac.uk/jilt/01-2/ penfold.html.

REIDENBERG, Joel R. (2001) "The Yahoo! case and the international democratization of the internet" Fordham University School of Law, Research Paper, núm. 11.

SÉDALLIAN, Valérie (2000) “Commentaire de l'affaire Yahoo!: à propos de l'ordennance du tribunal de grande instance de Paris du 22 mai 2000", Francia: Juriscom, en www.juriscom.net

TANTUICO, Delia (2001) "Governance in cyberspace: several different models are working side by side", Intermedia, may/june, núm. 29.

UNESCO (2000). The International Dimensions of Cyberspace Law, england: UNESCO/ASHGATE.

US District Court Decision (2001) "About Yahoo vs la Ligue contre le Racisme et l'Antisémitisme", a French Association et al.

US 9th District Court Decision (2006) "About Yahoo vs la Ligue contre le Racisme et l'Antisémitisme, a French Association et al.

WALLACE, Jonathan, Mangan Mark (1997) Sex, laws and cyberspace, New York : Henry Holt and Company.

WERY, Etienne (2000) “Aspects internationaux du réseau (DIP): à propos de l'affaire Yahoo!, Francia: droit et nouvelles technologies", en http://www.droit-technologie.org

YAHOO! (2000) Complain for Declaratory Relief, US. 